\title{
Psicodinâmica do estresse: estudo com trabalhadores de pesquisa, desenvolvimento e inovação
}

\author{
Psychodynamics of stress: a study among workers in research, \\ development, and innovation \\ Psicodinâmica del estres: estudio con trabajadores de investigación, \\ desarrollo e inovación
}

» José Henrique VILCHES NOGUEIRA ${ }^{1}$ (Empresa Brasileira de Pesquisa Agropecuária - Embrapa)

» Lêda Gonçalves de FREITAS² (Universidade Católica de Brasília)

Este estudo visa a investigar a psicodinâmica do estresse em trabalhadores de um centro de pesquisa de uma empresa pública brasileira de ciência, tecnologia e inovação. $O$ pressuposto que fundamenta esta investigação é de que o contexto produtivista contemporâneo, por meio do suporte ideológico de excelência, desempenho e produtividade, subverte o sentido do trabalho do cientista. Em face dessa subversão de sentido, o sofrer comparece pelo termo estresse, empregado em sentido amplo. Neste estudo, o estresse foi tomado como representante da sobrecarga e, para a coleta de dados, utilizamos a abordagem qualitativa. Um grupo de dez participantes voluntários foi formado e sete entrevistas coletivas foram realizadas. Os dados foram considerados a partir da técnica de análise dos núcleos de sentido (ANS). Com base nos resultados, a atribuição de sentido vincula o estresse à sobrecarga de trabalho. No âmbito do sofrimento, consigna sensações de esgotamento físico ou emocional, jornadas duplas, agregação de funções burocráticas às técnicas, ausência ou precariedade de condições, meios físicos ou psíquicos para a realização do trabalho e percepção de ausência ou precariedade de tempo. Já no campo das estratégias defensivas, há o movimento da autoaceleração, da negação, da racionalização e da idealização. E no das patologias contemporâneas, quando a sobrecarga se configura em face da centralidade do trabalho pela exacerbação da necessidade de reconhecimento, o estresse consigna a idealização individual afetiva de herói e o imaginário social generalizado da ciência com alto grau de certeza.

Palavras-chave:

Psicodinâmica do trabalho; estresse; pesquisadores.

\section{Abstract}

This study aims to investigate the general psychodynamics of stress among workers in a research center of a Brazilian public technological innovation company. The assumption underlying this research is that the productivist contemporary context, through the ideological support of excellence, performance, and productivity, subverts the meaning of the work of the scientist. Given this change in meaning, suffering appears by means of the term stress, used in a broad sense. In this study, stress was taken as representative of work overload. To collect data, we used a qualitative approach. We set up a group of ten volunteer participants and conducted seven collective interviews. Data analysis used the technique of analysis of units of meaning $(A N S)$. Based on the results, the attribution of meaning links stress to work overload. In the context of suffering, it represents sensations of physical or emotional exhaustion; difficulties in separating what is inside and outside of work; double shifts; the aggregation of bureaucratic functions with technical functions; lacking or poor physical or mental conditions for carrying out the work; perception of lack of time. In the area of defensive strategies, there is the movement of self-acceleration, denial, rationalization, and idealization. In the area of contemporary pathologies, when overload takes shape in the context of the centrality of work by exacerbating the need for recognition, stress is expressed as individual affective idealization of a hero and the imaginary social generalization of science with a high degree of certainty.

Keywords:

Stress; psychodynamics of work; researchers.

\footnotetext{
1 Graduado em Psicologia, mestre em Psicologia pela Universidade Católica de Brasília. Empresa Brasileira de Pesquisa Agropecuária - Embrapa. Email: henrique.vilches@gmail.com

2 Doutora em Psicologia, professora titular da Universidade Católica de Brasília. Email: ledagfr@gmail.com
} 
Este estudio pretende investigar la psicodinámica del estrés en los trabajadores de un centro de investigación de una empresa brasileña estatal de ciencia, tecnología e innovación. El supuesto que fundamenta esta investigación supone que el contexto productivista contemporáneo, sustentado en el soporte ideológico de la excelencia, el rendimiento y la productividad, subvierte el sentido del trabajo del científico. Ante este cambio de sentido, el sufrimiento se presenta bajo la denominación de estrés, empleado en el sentido más amplio. En este estudio, se tomó al estrés como indicador de la sobrecarga. Para la colecta de datos, utilizamos una aproximación cualitativa. Formamos un grupo de 10 sujetos participantes voluntarios y realizamos 7 entrevistas colectivas. Para el análisis de datos se utilizó la técnica de análisis de núcleo de significados (ANS). Con base en los resultados, la atribución de sentido relaciona el estrés a la sobrecarga laboral. Cuanto al sufrimiento, se consigna sensaciones de agotamiento físico y emocional; doble turno laboral; agregación de funciones burocráticas además de las técnicas; condiciones de trabajo precarias o inexistencia de los medios físicos o psíquicos para realizar el trabajo; percepción de la ausencia o precariedad en el tiempo. En el campo de las estrategias defensivas, aparece el movimiento de la auto-aceleración, de la negación, de la racionalización y de la idealización. En el campo de las patologías contemporáneas, cuando la sobrecarga se configura como punto central del trabajo por la exacerbación de la necesidad de reconocimiento, el estrés consigna la idealización individual afectiva del héroe y del imaginario social generalizado de la ciencia con un alto grado de certidumbre.

Palabras-clave:

Psicodinámica del trabajo; estrés; investigadores.

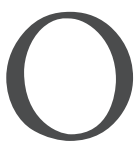

pressuposto que fundamenta a investigação é de que o contexto produtivista contemporâneo (Alves, 2011; Antunes \& Alves, 2004; Dejours, 1992, 2012b; Pinto, 2010; Schirato, 2004), por meio do suporte ideológico de excelência, desempenho e produtividade (Dejours, 2004/2008h, Mendes, 2007a, Pinto, 2010), subverte também o sentido do trabalho do cientista, afetando o paradoxo estabelecido entre prazer e sofrer. Em face dessa subversão do sentido do trabalho, o sofrer comparece aos pesquisadores pelo termo estresse. Empregado em sentido amplo, o estresse representa a sobrecarga, o sofrimento refletido em diversas expressões e é responsável pela constituição de estratégias defensivas.

Com base nesse pressuposto, compreendemos que, no centro da atual configuração do trabalho, o contexto produtivista com base na lógica da maximização do lucro propõe a todas as categorias profissionais, inclusive aos trabalhadores de ciência, uma busca implacável e extenuante por excelência, desempenho e produtividade. A materialização desse conjunto de pensamentos nas organizações do trabalho ocorre por meio de modelos científicos de gestão. No extremo do racionalismo, esses modelos comportam a reificação do homem, tornando-o mera extensão da máquina, ou a apropriação total da subjetividade do trabalhador, fazendo do desejo da organização o seu próprio desejo.

Para a psicodinâmica do trabalho, transmutar o sofrer implica repensar a organização do trabalho em vias de oferecer aos trabalhadores espaços de mobilização coletiva do sofrimento (Mendes, 2008). A organização do trabalho torna-se o lugar de aprendizagem da democracia, da construção de regras que não visam apenas ao sucesso de produzir de modo conjunto, mas à compreensão do outro, ao viver coletivamente e à civilidade (Dejours, 2012b).

O estresse caracterizado pelo sofrimento no âmbito do trabalho tem sua investigação privilegiada por uma leitura positivista, por meio de epistemologias objetivas e de pressupostos teóricos Cognitivo-comportamentais (Peçanha, 2009, Zanelli, 2010). Tal investigação é carente de leituras capacitadas aos aspectos subjetivos e simbólicos e aos processos interpretativos presentes na relação homem-trabalho. Por isso, este estudo buscou privilegiar a atribuição de sentidos, a fluidez e a mobilização da subjetividade dos participantes para reconstruir o drama vivido na realidade atual do trabalho de pesquisador. Por meio da epistemologia da psicodinâmica do trabalho, o estresse foi tomado em função da sobrecarga e das decorrentes relações com o sofrimento, com as estratégias defensivas e com as patologias contemporâneas.

Foco de nosso interesse, a categoria dos pesquisadores é representada, no Ministério do Trabalho e Emprego (MTE), por um conjunto diverso de atividades profissionais, variando conforme o contexto de atuação. De forma geral, eles elaboram e gerenciam projetos (ou laboratórios); realizam procedimentos de coleta, de tratamento, de análise de dados e de informações; criam metodologias, técnicas, equipamentos e ferramentas (pesquisa experimental); constroem sistemas, modelos e teorias (pesquisa básica); disseminam conhecimentos e; formam recursos humanos. Por fim, atuam de forma individual ou em equipes, com profissionais de mesma 
formação ou multidisciplinares e da mesma instituição ou em redes de organizações (Ministério do Trabalho e Emprego [MTE], 2010).

A preocupação com os problemas de saúde mental e com o sofrimento psíquico no trabalho constituiu o ponto central que norteou e justificou este estudo de caso. Para Dejours (2004/2008a, 2004/2008c, 2004/2008d), tem sido grande o interesse pelos problemas suscitados no vínculo trabalho-saúde, particularmente, considerando a percepção de que os trabalhadores atuais parecem mais vulneráveis aos efeitos deletérios do trabalho do que os do passado. Por meio da epistemologia da psicodinâmica do trabalho, o estresse foi tomado em função da sobrecarga e das decorrentes relações com o sofrimento, com as estratégias defensivas e com as patologias contemporâneas.

\section{A psicodinâmica do trabalho}

São diversos os métodos e as abordagens para o estudo das relações entre trabalho e saúde mental (Merlo \& Mendes, 2009). No entanto, poucas se propõem a investigar os aspectos invisíveis da atividade, ou seja, as relações subjetivas do trabalhador com sua atividade, com o coletivo e com a organização do trabalho (OT), a afetividade sempre presente no ato de trabalhar (desejos, medos, amores, paixões), a dinâmica estabelecida pelo dualismo sofrer-prazer e as estratégias psíquicas desenvolvidas para a defesa contra o sofrimento (Dejours, 2004/2008b, 2012b).

A psicodinâmica do trabalho, abordagem científica de caráter clínico, articulada com a sociologia teórica e com a teoria social, estende-se à desordem e à indeterminação daquilo que não está na superfície, mas que se revela pela atribuição de sentidos com base nas vivências intra e interpsíquica do sujeito e na fluidez de sua subjetividade nas relações sociais do trabalho. A construção do conhecimento é embasada pela dinâmica dos seguintes construtos: organização do trabalho, prazer, sofrimento e estratégias defensivas. Tal movimento revela patologias do sofrimento contemporâneo no trabalho.

Repleta de contradições, a organização do trabalho toma lugar especial na análise psicodinâmica como significante do real do trabalho conflitando o afetivo dos trabalhadores (Dejours, 2012a, 2012b). A relação do homem com a OT pode ser entendida como um sistema aberto cuja natureza precária exige sucessivos deslocamentos rumo ao equilíbrio e à estabilidade, contudo, apenas aparente (Dejours, 2004/2008b).

Mediando a construção da saúde, o prazer está relacionado ao exercício da inteligência criadora e ao reconhecimento da contribuição fundamental do trabalho para a organização. Implica a possibilidade sublimatória, ou seja, a substituição da meta sexual por atividades consideradas socialmente úteis, e a perspectiva da cultura (Dejours, 2004/2008f, 2004/2008i, 2012a, 2012b). Como fonte de prazer, o trabalho é capaz de gerar a realização de si mesmo, a identidade, o reconhecimento e a liberdade, situação que pressupõe a existência de indivíduos capazes de ação não somente por seus desejos, mas também pelas condições propiciadas pela organização desse mesmo trabalho (Mendes, 2008).

Dejours (1992, 2004/2008c, 2004/2008i) e Mendes (2007a) enunciam o sofrimento no âmbito da restrição, ou seja, de bloqueios na relação homem-trabalho, particularmente pela carência ou pela inexistência de possibilidades de negociações quando os conflitos se tornam intransponíveis, da inexpressividade da inteligência criadora e de desejos dos indivíduos e da ausência de reconhecimento.

Perante a realidade do trabalho, continuamente conflitando e provocando o sujeito, sempre haverá sofrimento, diferindo o destino na medida das condições favoráveis à organização do trabalho para negociações e transformações (Dejours, 2004/2008j, 2012b). Na presença desse sofrimento e em busca de não adoecer, os trabalhadores desenvolvem estratégias de defesa: um conjunto de condutas de convivência com o sofrer. As defesas representam a forma e o destino dado ao sofrimento, configurando-se como meio privilegiado de acesso ao sofrer (Dejours, 1992, 2004/2008b, 2004/2008d, 2004/2008g).

Tais estratégias defensivas ocorrem em todos os níveis hierárquicos da organização do trabalho, não sendo privilégio das carreiras e dos cargos mais baixos da hierarquia organizacional. Do mesmo modo, elas transcendem o espaço privado e a economia familiar devido à impossibilidade de separar o dentro-do-trabalho do fora-do-trabalho quando o funcionamento psíquico ocorre de modo indivisível (Dejours, 2004/2008g). Na concepção dejouriana, essas estratégias de defesa podem ser construções individuais ou coletivas, assim, não apenas dependem da maleabilidade individual, mas comportam formas específicas de cooperação (Dejours, 1992, 2004/2008a; Mendes, 2007a). 
Para Dejours (2012b), a cooperação no trabalho diz respeito à implicação dos sujeitos na elaboração e no ajuste das regras, abrangendo as deliberações coletivas que favorecem o trabalhar. É um processo de convivência que envolve compreensão mútua dos saberes-fazeres; envolve confiança, pois, na obra comum, pode haver exposição, revelação de segredos, como a expertise singular, por exemplo; e envolve controvérsias e arbitragens, consentimentos e disciplina. Assim, muitos são os espaços de deliberação coletiva que possibilitam a expressão das críticas nascidas da experiência do trabalho em prol de soluções para as contradições entre o real e o prescrito. Esses espaços são fundamentais à produção das regras que estruturam a cooperação e à conciliação das condições propícias à perlaboração.

No rol das enfermidades contemporâneas, articuladas aos jogos de dominação da organização pela definição da carga de trabalho e pela propagação ideológica da excelência e do desempenho - relacionadas à disciplina da fome e à centralidade do trabalho - as patologias de sobrecarga abrangem distúrbios musculoesqueléticos (LER/Dort, problemas psicossomáticos), síndrome de burnout (estresse em nível de completa exaustão emocional e profundo sentimento de frustação) e karoshi (espécie de morte súbita ocupacional, por acidente vascular cerebral ou cardíaco, vinculada ao estresse).

No campo das compulsões, a hiperatividade profissional implica a dependência psíquica em relação à atividade e à incapacidade de gozar o repouso. Tal condição afeta o jogo da fantasia, da imaginação e da afetividade, colocando em risco a subjetividade do trabalhador (Dejours, 2004/2008e, 2004/2008h; Mendes, 2007b).

\section{O estresse, a psicodinâmica do trabalho e o modelo condutor da investigação}

A perspectiva conceitual do estresse contempla um conjunto de representações do qual é relevante considerar as ideias do físico Inglês Robert Hooke (1635-1703) quanto à capacidade de uma estrutura suportar mudanças de cargas e demandas externas (Lazarus, 1993); a proposta de Canon (1914 citado em Sardá, Legal, \& Jablonski, 2003) quanto à reação do indivíduo frente às situações "lutar-fugir"; o modelo de Hans Selye (1907-1982) para a síndrome da adaptação geral (SAG) quanto às necessidades e às capacidades adaptativas do indivíduo (Selye, 1950; Cooper, Dewe, \& O'driscoll, 2001); e as perspectivas de Richard S. Lazarus (19222002) a respeito da avaliação emocional e cognitiva do sujeito, influenciando nas estratégias para lidar com as demandas do ambiente (Lazarus, 1990, 1993, 2006).

Tal contexto nos possibilitou compreender o estresse como um processo de busca por regulações homeostáticas em face das tensões efetuadas nas relações entre o sujeito e o ambiente, portanto, inerente à vida. Refletido em nossa vida física, psíquica e social (Lazarus, 2006), o estresse integra a dinâmica do trabalho. Nesse espaço, de modo geral, as pesquisas estão inseridas no paradigma positivista, baseadas em pressupostos teóricos cognitivo-comportamentais. As ações de saúde decorrentes se voltam ao gerenciamento individual e ao treinamento contra o estresse (Peçanha, 2009). Essa perspectiva é frontalmente criticada por Dejours (2004/2008h), que aponta a gestão do estresse comportamental - em práticas discursivas que visam apenas à atenuação do sofrimento - como uma das novas formas de dominação do mundo do trabalho em face da capacidade de distanciamento do pensamento crítico e, por consequência, das possibilidades do agir e do criar. A psicodinâmica do trabalho revela o estresse no âmbito do sofrimento e sua manifestação sintomática em patologias (Mendes, 2007a; Mendes, Paz, \& Barros, 2003; Uchida, 1998), particularmente as de sobrecarga (Dejours, 2004/2008e, 2004/2008h).

Neste estudo, o estresse foi compreendido em decorrência das relações dinâmicas constituídas entre a organização do trabalho e o sujeito-trabalhador. Buscando constituir um modelo teórico para conduzir a investigação, assumimos a suposição de que o contexto produtivista contemporâneo e seu suporte ideológico têm relação com a organização do trabalho e com o paradoxo prazer-sofrer. Em tal contexto, o estresse relaciona-se à sobrecarga de trabalho nos âmbitos do sofrimento, das estratégias defensivas e das patologias contemporâneas.

A circunscrição do sofrimento contempla sensações de esgotamento físico ou emocional, dificuldades em separar o dentro e o fora do trabalho, jornadas duplas e agregação de funções burocráticas às técnicas. Em referência às estratégias defensivas, o estresse ocorre pelo movimento da autoaceleração e suas manifestações: hiperatividade sensório-motora, aumento na carga de trabalho, embotamento do pensamento ou da afetividade, doenças psicossomáticas, impossibilidade de uso da ociosidade e dificuldade de participação em atividades lúdicas. 
Para Rego (2013), a dinâmica da estratégia de aceleração das cadências de trabalho envolve a redução do tempo ao realizar tarefas sem sentido. Nesse contexto, o sujeito que trabalha não reflete sobre o seu fazer, com efeito, a monotonia e a pressão por resultados, mas aumenta a produtividade, obtendo prazer mediado pela dinâmica do reconhecimento.

\section{MÉTODO}

\section{Participantes}

O estudo de caso foi realizado com dez trabalhadores de pesquisa, desenvolvimento e inovação em um centro de pesquisa de uma empresa pública brasileira de ciência, tecnologia e inovação (CT\&I). Este projeto foi aprovado pelo Comitê de Ética em Pesquisa da Universidade Católica de Brasília - UCB, número do protocolo CAEE 05837412.0.0000.0029, Parecer 86298 (27/08/2012).

\section{Instrumentos}

Para Mendes e Araújo (2011), stricto sensu, o método clínico da psicodinâmica do trabalho pressupõe a sucessão de quatro dispositivos básicos: a demanda formulada pelos interessados e traduzida pelo(s) pesquisador(es); a elaboração e a perlaboração, processo catalizador do pensamento capacitado à reconstrução de significados; a construção de laços afetivos aptos aos movimentos da transferência (pedidos de amor, identificação, reconhecimento, agressividade); e a interpretação como forma de lidar com o sistema defensivo em busca de novos modos de ação sobre o sofrimento.

Em face da exigência de adaptações à realidade acadêmica - particularmente, pelo fato de a demanda inicialmente ter sido oriunda dos pesquisadores e, posteriormente, apresentada aos sujeitos-participantes até a congruência com suas expectativas e necessidades e a condicionante restritiva aos tempos com repercussões nos processos de elaboração-perlaboração e de mobilização subjetiva -, este estudo foi categorizado como teórico. No entanto, os meios e os modos de conduzir a investigação foram inspirados na concepção filosófica reivindicatória e participativa em sua perspectiva clínica de análise da realidade, especialmente considerando como fonte de conhecimento o diálogo crítico dos sujeitos-participantes, suas ações recursivas e paradoxais e suas vivências intersubjetivas no trabalho. Buscou-se a constituição do espaço coletivo de discussão e, na medida do possível, o favorecimento de mobilizações subjetivas rumo à ressignificação do sofrimento e ao prazer no sentido do trabalho vivo, aproximando-se da categoria teórico-metodológica da psicodinâmica do trabalho.

\section{Procedimentos de coleta de dados e cuidados éticos}

Esta pesquisa envolveu coleta dos dados, com sete entrevistas coletivas como espaço de fala e escuta, contemplando: a) a assinatura do Termo de Consentimento Livre e Esclarecido (TCLE) por todos os sujeitosparticipantes e a construção da agenda de funcionamento do grupo; b) o retorno da análise documental e das observações realizadas durante a pré-pesquisa ao grupo; c) a negociação e a instituição das regras de conduta do grupo e do contrato psicológico; d) a constituição do espaço de fala e escuta, correspondendo à totalidade das entrevistas coletivas realizadas (no início de cada encontro era apresentada a síntese do anterior para validação dos participantes); e e) a análise e organização dos dados e a apresentação dos resultados para todos os participantes do estudo.

\section{Procedimentos de análise de dados.}

Para consideração dos dados, utilizamos a técnica da análise dos núcleos de sentido (ANS), uma adaptação de Mendes (2007c). Com a finalidade de agrupar os conteúdos latentes e manifesto do discurso em temas que se desmembram em núcleos de sentido, concedendo suporte às interpretações, a ANS caracteriza uma forma particular de olhar os dados, incorporando às particularidades da comunicação oral ou escrita, figuras de linguagem em seus paradoxos, metáforas e chistes (Mendes, 2007c).

\section{RESULTADOS E DISCUSSÃO}

Os resultados foram organizados em dois núcleos de sentidos, sendo apresentada uma descrição em cada um e, concomitantemente, será feita a discussão. 


\section{"A gente, na verdade, é uma locomotiva. E o que tem em uma locomotiva?"}

De modo geral, esse núcleo de sentido circunscreve a sobrecarga do trabalho do pesquisador e revela as vivências de sofrimento profissional. Tal situação comporta perspectivas afetivas associadas à escolha amorosa da profissão, permeada por reminiscências da infância e perspectivas imaginárias, idealizações heroicas e suas posições narcísicas. $\mathrm{Na}$ demanda percebida como exagerada, surge o princípio da realidade e, com ele, as contradições da organização, caracterizando elementos da dinâmica prazer-sofrer e das estratégias defensivas. No discurso, o sentimento de dignidade que a profissão de pesquisador pode oferecer à humanidade demonstra idealizações, como a de ser especial, de ser diferente ou de conviver com seres extraordinários. "Esse cara deve ser um ser humano totalmente diferente... Algo de outro universo... Surreal... Algo para poucos, não para qualquer um" (comunicação pessoal, outubro, 16, 2012).

Esses traços do discurso também podem ser considerados como um sonho profissional além da produção orientada ao mundo concreto (poiesis). Oportunidade que nos possibilita refletir a respeito da ideia dejouriana da dupla centralidade do trabalho: uma que se vincula à poiesis, notadamente considerada quando o trabalho é tomado como objeto de estudo; e outra ao arbeit freudiano, o trabalho como espaço de inscrições na subjetividade - mobilização subjetiva -, em que, por meio da perlaboração e do remanejamento do corpo erógeno, o sujeito se transforma (Dejours, 2012a).

De outro modo, no campo imaginário, o herói idealizado por suas qualidades e valores, que tende à perfeição, torna o pesquisador suscetível à armadilha narcísica, segundo Lambotte (1996), em que a imagem refletida pelo olhar do outro, a quem o sujeito, apaixonado, aliena seu eu em busca da correspondência ideal. Os pesquisadores são profissionais exigentes consigo. O ideal amoroso da profissão conduz à busca constante por responder à altura, implicando em forte autocrítica e exageros na cobrança de si. "A gente quer fazer mais e mais [...] A autocrítica é tremenda. A gente se cobra muito" (comunicação pessoal, outubro, 16, 2012).

O trabalho não é uma atividade que depende unicamente do eu (ato solipsista), pelo contrário, ele é feito para e com o outro, portanto, sempre relacional (Dejours, 2012a). Diante dessa perspectiva, transmutados pela cobrança demasiada de si, os sentimentos pessoais de dívida isolam o pesquisador, que passa a se responsabilizar sobremaneira pelo alcance dos objetivos conferidos a ele. O controle é internalizado no trabalhador.

No âmbito imaginário, a posição idealizada do herói é ilusória. Desconsidera, como menciona Mendes (2007b), o jogo da organização do trabalho regido pelo contexto ideológico contemporâneo de excelência, desempenho e produtividade, cujos efeitos perversos podem conduzir o trabalhador às patologias da sobrecarga. A ilusão heroica é capaz de converter em sofrimento o prazer de agir sobre a realidade precária do outro. Quando o real comparece e o imaginário do herói é quebrado pela ausência de recursos, o trabalhador se sente frustrado e impotente. Esse sofrimento é citado por profissionais de referência em saúde mental, conforme estudo de Silva e Costa (2010).

Os pesquisadores relatam serem exigidos de maneira muito rígida, destacando a pressão das expectativas depositadas pela sociedade. O peso dessa carga mobiliza a necessidade de reação, pois, do contrário, sobrevirá o estresse. "Nós somos cobrados de maneira muito rígida. Temos de arrumar um meio de tratar essas coisas, senão nos estressamos” (comunicação pessoal, novembro, 20, 2012).

Diferentemente do imperativo desejoso de "fazer retornar resultados à sociedade", tomado como imaginário heroico, a rigidez da cobrança oportuniza despontar o real do trabalho por suas contradições. A percepção da realidade comparece no registro da frustação quando é obliterada a possibilidade de satisfação do desejo do outro. Nesse caso, o outro é percebido como inflexível e demandante de tarefas que não são simples, ou possíveis, de serem realizadas. Para atendê-las, faz-se necessário percorrer longos caminhos, executar múltiplas tarefas por vezes árduas e colocar em prática a inteligência e a astúcia. Por mais similar que seja à jornada do herói, as contradições da realidade sinalizam o possível esgotamento, situação a qual é necessário manter atenção. Descrevendo suas atividades cotidianas, os pesquisadores recorrem ao recurso metafórico e trazem o mito de Hércules e seus 12 trabalhos. Ser pesquisador exige um rol extenso de atividades. "São as 12 provas de Hércules. A gente tem de pensar, administrar, ter criatividade, executar, conhecer qual a dinâmica, os procedimentos para solicitar coisas" (comunicação pessoal, outubro, 16, 2012).

Assim, Hércules nos fala da sujeição ao outro pelo dever, daquele obrigado a se empenhar em uma jornada de diversos trabalhos, envolvendo muitas lutas e, sobretudo, o uso de força excepcional, pois o herói necessitou até mesmo sustentar o firmamento no lugar do titã Atlas. Esse personagem traduz o embate laboral travado entre a obrigação amorosa e a moral de buscar soluções à sociedade e à diversidade, ao volume e ao peso dos 
esforços envolvidos direta e indiretamente na lida do pesquisador, reclamando the cair tudo sobre as costas. Assim, é possível entendê-lo como representante da sobrecarga vivenciada. Dejours (2004/2008e) alerta sobre o fato de a sobrecarga de trabalho colocar em risco os jogos da fantasia, da imaginação e da afetividade.

O controle é esgotante, e o pesquisador não pode falhar. Contingências não são aceitas, pois deveriam ter sido exaustivamente previstas. Caso o experimento não chegue a termo, não há resultados, e isso não se justificativa perante si mesmo, os pares, a organização do trabalho ou a sociedade. "Eu não posso falhar, então acaba pesando um bocado... Por que eu não posso falhar? Porque depois eu não consigo executar o trabalho. Eu vou tentar fazer algo novo e eles não vão querer trabalhar comigo" (comunicação pessoal, mês novembro, 20, 2012). A carga da rigidez aparece também na exigência da organização do trabalho por um controle com proporções maiores do que a realidade de ação do pesquisador. Dejours (1992) relaciona a fragilização psicossomática do trabalhador à rigidez no trabalho.

O conceito dejouriano de trabalho vivo toma o fracasso como a experiência de confronto com o real, experiência à qual o trabalhador resiste. Por meio da mobilização de sua subjetividade, ele transforma a realidade e a si mesmo. Essa espécie de conversão leva à sublimação: "Faz do trabalho - poiesis - uma promessa: a de uma ampliação da subjetividade - arbeit - que abre caminho para a realização de si mesmo" (Dejours, 2012b, p. 20). Mendes (2007a), por sua vez, observa que o sofrimento surge na proporção das impossibilidades de negociações entre o trabalhador e a realidade imposta pela organização.

A impossibilidade de falhar revela um estado de vigilância contínua sobre o trabalho do outro, particularmente aquele executado pelos trabalhadores da carreira de suporte à pesquisa. Pela dúvida, que se torna uma constante, a gestão do projeto toma contornos obsessivos. "Na verdade, se você quiser fazer acontecer, você tem de ter um trabalho extremo de vigilância e de supervisão. É exaustivo" (comunicação pessoal, novembro, 20, 2012).

A confiança é uma das grandes dificuldades para o trabalho coletivo, que é capaz de reunir as inteligências individuais na dinâmica grupal. Confiar implica correr riscos, entre eles o de expor falhas no saber-fazer (Dejours, 2012b).

Não é possível, e nem é nosso objetivo, negar a relação direta ou indireta de falhas em outras instâncias da organização com insucessos no trabalho do pesquisador, devendo elas serem objeto de discussão e deliberação do coletivo e de ajustes da organização do trabalho. No entanto, propomo-nos a refletir a respeito do impacto devastador que a falha é capaz de trazer ao corpo erógeno do pesquisador, atingindo o reconhecimento de seu trabalho. Esse aspecto nos leva a refletir sobre a intensidade do grau do reconhecimento do outro no trabalho do pesquisador, traçando um limite tênue entre obtenção de prazer e constituição de sofrimento. Segundo Mendes (2007b), quando o trabalho se torna central em face da necessidade exacerbada de realização e reconhecimento - elementos nucleares da identidade, da subjetividade e da emancipação -, a sobrecarga ocorre pela submissão incondicional às demandas da organização do trabalho, mesmo para além das condições físicas, psicológicas e sociais do trabalhador.

Os pesquisadores, por sua vez, relatam que "tudo lhes cai sobre as costas" (comunicação pessoal, novembro, 13, 2012), pois, além de exercerem múltiplos papéis, devem conhecer áreas muito diferentes de seu saber. Na busca pela perfeição, preocupam-se com tarefas que poderiam estar sob a responsabilidade de outro, que é percebido como ausente, e essa situação conduz o pesquisador à sensação de solidão.

O que mata é a gente ter que se preocupar com muitas coisas, buscando a perfeição... Você tem de se preocupar com a cotação do dólar, o leite, o cafezinho, a bolacha, o trânsito e não sei mais o quê?? Isso é sobre-humano. Mata as pessoas. Dá uma sensação de solidão, desamparo, desespero (comunicação pessoal, novembro, 20, 2012).

A locomotiva oferece uma visão da carga como excessiva, ora pela obrigação de tudo saber, ora pela assunção ou participação em tarefas que o pesquisador julga fora de seu limite de responsabilidade. A busca pela perfeição representa a impossibilidade de falhar. Faz a obsessão voltar, não pela dúvida, mas pela obrigação do senso moral da profissão e do imperativo afetivo-produtivo de dar retorno. A agregação de funções burocráticas às técnicas é causa de sofrimento entre enfermeiros que trabalham em unidades de terapia intensiva. Sobrecarregados, esses profissionais entendem que a execução da atividade acessória relativiza a atividade principal (Bomfim \& Soares, 2011). 
À multiplicidade de tarefas se junta à percepção de burocracia demasiada, com implicações negativas para o sentimento de autonomia. "A gente entra em esferas que não são as nossas exatamente... Essa parte burocrática me estressa... Estar sempre ligado às adaptações para poder executar nossa atribuição... Se gasta um tempo muito grande com outras coisas" (comunicação pessoal, outubro, 16, 2012). As queixas em relação à burocracia presentes no discurso dos pesquisadores corroboram os achados de Câmara e Faria (2009), que indicaram, entre outros aspectos, o comprometimento do fluxo de trabalho pelo excesso de burocracia na empresa de CT\&I investigada por elas.

Protagonizar o comboio, lugar da locomotiva, implica também pagar o preço do desconhecimento e, pelo desgaste, consumir energia suficiente para ameaçar a vida. Para viabilizar a manutenção do desejo, a organização precisa fornecer o apoio necessário. Quando o pesquisador se defende da sobrecarga, ele sofre por se sentir menos trabalhador.

Já quis ser locomotiva. Sou vagão faz tempo. Vagão vazio, às vezes. E assim, desse jeito, eu me envergonho. O que eu tenho feito é muito pouco... Diminui as expectativas, desacelerei o ritmo para gerenciar as eventuais, vamos chamar, frustraçôes... Eu me sinto menos trabalhador(a) (comunicação pessoal, outubro, 16, 2012).

As situações reais de trabalho são complexas e polivalentes, e o sofrimento pode andar ao lado do prazer (Dejours, 2004/2008f). Desse modo, ser locomotiva também é carga de grande sofrimento. Ir sozinho à frente dos demais sem a percepção de uma retaguarda de apoio pode conduzir o pesquisador ao esgotamento derradeiro, e implica em momentos de frustação e sensações de insegurança.

O sofrimento exposto guia o sujeito para a percepção de ser sofrente, condição necessária à inquietação e à desestabilização, circunstâncias indispensáveis à mobilização, tendo em vista as (re)construções do trabalho (Mendes \& Araujo, 2012). Do contrário, para não sofrer e sucumbir ao adoecimento, o trabalhador se vê obrigado a utilizar estratégias de defesa (Dejours, 1992, 2004/2008b, 2004/2008d). Para se adaptar à ausência de apoio, à sensação de exposição contínua a situações de estresse e insegurança que essa ausência traz e a eventuais frustrações, ironia que revela força de constância, o pesquisador busca negar e conter o seu desejo. No entanto, o preço dessa tentativa de atenuação do sofrer é muito alto, pois repercute diretamente no prazer que o trabalho é capaz de proporcionar: a realização de si, o fortalecimento da identidade e o reconhecimento. O pesquisador se sente menos trabalhador e, com isso, fecha um círculo vicioso de sensações: sobrecarga, frustração, insegurança e inutilidade.

Diferente do que ocorre com a carreira de suporte à pesquisa, o termo vagão deixa de ser uma alegoria de carga quando referencia a possibilidade de composição de pares entre pesquisadores. "É importante o trabalho em equipe. Às vezes, você não é locomotiva, você é vagãa, mas está no mesmo comboio... Quando tem uma vitória dele e eu faço parte da equipe, por extensão também é uma vitória minha..." (comunicação outubro, 23, 2012)

Para Dejours (2012a, 2012b), o trabalho coletivo é o elo entre a atualização individual (realização de si, posição narcísica) e a contribuição para a polis e a cultura ("amor mundi", postura moral, civilidade e viver junto). Ele é constituído pela mobilização das inteligências singulares em prol de uma dinâmica comum. Tal contexto de trabalho pressupõe o agrupamento pela liberdade da vontade individual em prol da obra coletiva, privilegiando a constituição de espaços de deliberação públicos nos quais se dará a construção das regras do viver e do produzir em conjunto, a controvérsia - formulação e defesa do saber-fazer individual - e a resolução dos problemas, por consenso ou arbitragem. Essa situação é bem diferente daquela caracterizada pelo esforço objetivo que busca compatibilidades técnicas e instâncias autorregulatórias, como ocorre, por exemplo, nas equipes de trabalho enviesadas pela ideologia da gestão toyotista (Dejours, 2012a, 2012b).

O pesquisador apaixonado estende a carga horária para um extremo simbólico de 24 horas. Essa autoaceleração recorta negativamente o usufruto da ociosidade e o ritmo de sono e embota a afetividade das relações familiares e sociais.

Eu ficava pilhado(a) com as coisas do trabalho. [...] Depois que eu me separei, eu mudei um pouco minha postura. Eu pude parar e pensar um pouquinho... A culpa é da gente, mas a empresa rebate na gente e isso repercute lá fora (comunicação pessoal, novembro, 20, 2012). 
Amorosamente idealizado, o desejo da locomotiva é fonte de prazer para o pesquisador, mas carga de sofrimento também. A idealização imaginária da perfeição faz retornar a posição narcísica da onipotência, à qual se soma a possibilidade de exacerbação da necessidade de realização e reconhecimento. $\mathrm{O}$ desejo do pesquisador é sintônico ao desejo da organização do trabalho. A posição narcísica de onipotência, a possibilidade de que as necessidades de realização e de reconhecimento estejam exacerbadas e a sintonia do desejo do pesquisador ao desejo da organização do trabalho constituem um conjunto de condições que, hipoteticamente, são coadunáveis à ideologia contemporânea de excelência, desempenho e produtividade. O pesquisador torna-se suscetível à ordenação da atividade laboral prescrita na organização do trabalho. A confluência dessas circunstâncias é capaz de conduzir o trabalhador à sobrecarga e, para se defender das implicações nocivas, ele se autoacelera.

Inicialmente, a autoaceleração foi citada como estratégia defensiva ao trabalho repetitivo, constrangido pelo tempo das linhas de montagem e pelo pouco espaço de mobilização da inteligência criadora e caracterizado pela paralisia do pensamento e da consciência da situação de sofrimento constante.

Entretanto, na contemporaneidade, ela "atinge, progressivamente, muitos outros trabalhadores, mesmo em atividade nos setores de serviço e gestão" (Dejours, 2012b, p. 64), como é o caso do ativismo encontrado em executivos do setor do comércio cujas tarefas têm natureza cognitiva e relacional (Dejours, 2012b). As consequências patológicas dessa condição se mostram no desgaste e no envelhecimento precoce do corpo e do intelecto, e assurgem as doenças somáticas pela ruína do desejo (Dejours, 2004/2008g). Em relação às dificuldades do trabalho, levamos para casa. A falta de flexibilidade psíquica e afetiva, a intolerância e a inaptidão para a fantasia presentes na autoaceleração pesam na economia amorosa e atinge os relacionamentos estabelecidos fora do espaço do trabalho: o convívio social e familiar (Dejours, 1992, 2012b).

A escala prevista para a locomotiva não pode sofrer atrasos, por isso há descontrole diante do inesperado. Os pesquisadores afirmam que o maior foco de estresse são os imprevistos que agravam a situação do tempo de trabalho já insuficiente para tamanha demanda.

O maior foco de estresse são os imprevistos... Desde um telefonema na hora em que você está concentrado, lendo e relendo. Quando começa um vaivém na sua sala... Quando você tem somente isso aqui de tempo e aparece um imprevisto, ai, é de lascar (comunicação pessoal, novembro, 20, 2012).

Por um lado, o imprevisto pode ser entendido como um representante da extenuação. Reafirma a condição da sobrecarga e aponta para o estado limite, quando o pesquisador se torna incapaz de lidar com as variáveis que se interpõem de forma aleatória ao seu desejo amoroso - produzir conhecimento e levar o bem à humanidade - e à obrigação moral de dar retorno e ser produtivo. Por outro, o imprevisto pode ser tomado como referência à ausência de condições para a realização do trabalho; nesse caso, ausência do tempo absoluto, marcado pelas convenções dos relógios e dos calendários, ou psicológico, que se constitui relativo diante das condições de percepção do sujeito. Tal situação é estressante e conduz ao sofrimento.

A locomotiva emite um silvo de alerta. Asseveram os pesquisadores que o estresse está aumentando, pois há maior pressão na atualidade. O enfrentamento das dificuldades circunda o âmbito individual. "Essa questão do estresse do pesquisador está aumentando cada vez mais. [...]Onde a gente vai chegar com todo esse estresse? Vamos ter um enfarto? Vamos deixar nossas famílias" (comunicação pessoal, novembro, 27, 2012).

A destituição do espaço público da palavra, incapaz de engajar os sujeitos implicados em uma ação coletiva, o esgotamento da solidariedade e a exacerbação da concorrência em todos os domínios da vida têm levado as pessoas aos espaços privados das psicoterapias (Dejours, 2012a). Os pesquisadores enfrentam as dificuldades do trabalho no âmbito individual, buscando fora da organização o fortalecimento de seu corpo físico e afetivo (erógeno).

"Acho que nós temos paixão pelo nosso trabalho [...] tem esse componente de amor mesmo pelo resultado final."

De modo geral, esse núcleo de sentido circunscreve o prazer do pesquisador. O lugar do beneficiário da pesquisa é central para o reconhecimento do pesquisador. "É fantástico a gente saber que o [referência ao beneficiário direto da pesquisa] reconhece isso [referência aos produtos do seu trabalbo" (comunicação pessoal, outubro, 23, 2012).

Os pesquisadores trazem expressões de êxtase para referenciar o valor do juízo dado por aquele que beneficia-se objetivamente do resultado de seu trabalho. Esse outro, cujo olhar tem força enorme, pode ser 
tomado como representante da paixão. Nesse caso, objeto de maior interesse, o beneficiário direto da pesquisa seria a razão pela qual "todo o sofrimento não é em vão" (comunicação pessoal, outubro, 16, 2012).

De outro modo, a psicodinâmica do trabalho evoca extremo valor ao reconhecimento, capaz de transformálo em prazer. Motor do desejo, como retribuição simbólica, o reconhecimento imprime sentido subjetivo ao trabalho, proporcionando ao trabalhador a realização de si mesmo e a edificação de sua identidade no campo social. A valorização social da atividade ocorre no teatro das relações sociais imanentes ao trabalho. Nesse sentido, a apreciação qualitativa do outro extravasa a sublimação de seu campo solipsista e puramente intrapsíquico (Dejours, 2012b).

Assim, a força do reconhecimento dos beneficiários da pesquisa em face da utilidade e da importância do que foi produzido pelo pesquisador pode ser entendida em relação ao espaço que ela confere à sublimação: o teatro social, um palco que faz durar a permanência do aplauso do bom espetáculo, cujo som retumbante transborda para o julgamento da utilidade concedido pelos superiores hierárquicos no âmbito da organização.

Ainda em relação a esse reconhecimento, os pesquisadores relatam que o produto final pode ser invisível aos beneficiários diretos e que o termo da pesquisa demanda períodos longos. "Não vou lançar um produto tão cedo na minha área. Talvez demore 30 anos... Então, eu não tenho o feedback do resultado. Você se empenha, empenha e empenha" (comunicação pessoal, outubro, 23, 2012).

Contextos de trabalho em que a visibilidade da produção encontra-se restrita por um longo período de tempo ou pela localização do cientista na cadeia de geração do conhecimento exigem tranquilidade para buscar espaços e formas de valorização do seu trabalho. "Muitas das nossas conquistas são... conquistas pequenas para os interesses da sociedade, mas, do ponto de vista pessoal, são pequenas conquistas que te dão força" (comunicação pessoal, outubro, 23, 2012) O jogo do reconhecimento corresponde ao envolvimento de outros atores. Aí, entram em cena os pares e os chefes. "Um dos retornos é o artigo cientiffo publicado. Outro é aluno defendendo mestrado e doutorado" (comunicação pessoal, outubro, 23, 2012).

A comunicação científica, tomada no sentido restrito do espaço das publicações e das orientações de mestrado e doutorado, oferece o teatro social que extravasa a sublimação para o julgamento da beleza, nesse caso, concedido pelos pesquisadores nos âmbitos intra e interorganizacional. O julgamento estético concedido pelos pares "oferece, em contrapartida da contribuição do sujeito para o conjunto da obra, uma retribuição em termos de identidade." (Dejours, 2004/2008g, p. 209). Tal reconhecimento imprime no sujeito a posse das qualidades e do saber-fazer da comunidade de trabalho à qual pertence. Oportuniza, ainda, um segundo nível de reconhecimento cujo efeito corrobora efetivamente a identidade para além do reconhecimento das qualidades comuns ao coletivo, reconhecimento por aquilo que o sujeito apresenta de diferente e pela condição original que imprime o traço de sua individualidade (Dejours, 2004/2008g, p. 209).

O reconhecimento dos pares foi relatado como fonte de prazer também no trabalho de bailarinos profissionais (Segnini, \& Lancman, 2011) e de professores universitários (Coutinho, Magro, \& Budde, 2011). No jogo do reconhecimento, os pesquisadores reivindicam ação da hierarquia. Para Dejours (2004/2008g), o jogo das relações sociais do trabalho envolve o reconhecimento dos superiores hierárquicos quanto à qualidade do trabalho realizado. São aqueles que estão no sentido vertical da relação que aferem o julgamento capital e incontornável sobre "a utilidade social, econômica ou técnica do trabalho feito pelo sujeito" (Dejours, 2004/2008g, p. 208). De modo semelhante ao reconhecimento da beleza, o reconhecimento da utilidade é essencial à saúde mental do pesquisador. Dele decorre a possibilidade de levar ao beneficiário da pesquisa o seu desejo de dar retorno à sociedade e, com isso, fazer algo pela humanidade.

\section{CONSIDERAÇÕES FINAIS}

A realização deste estudo, fundamentado na abordagem teórica da psicodinâmica do trabalho, possibilitou investigar a psicodinâmica do estresse em trabalhadores de pesquisa, desenvolvimento e inovação. Tal empreendimento exigiu caracterizar a organização do trabalho desses profissionais e examinar com atenção suas vivências de prazer e de sofrimento.

A organização do trabalho é revelada por experiências contraditórias individuais e coletivas vivenciadas pelos trabalhadores. Sua caracterização abrange percepções objetivas e vivências subjetivas em face da divisão das tarefas (conteúdos, modos operatórios, distribuições e prescrições) e dos homens (sistema hierárquico, modalidades de comando, relações de poder e responsabilidades). Caracterizando a organização do trabalho 
dos profissionais da pesquisa, desenvolvimento e inovação, consideramos, para a divisão da tarefa, a existência de três âmbitos.

O primeiro ocorre entre carreiras: a de pesquisa e a de suporte à pesquisa e ao desenvolvimento. $\mathrm{O}$ segundo e o terceiro na própria carreira de pesquisa: a locomotiva, o lugar do protagonista, e o vagão, posição intermediária de composição de equipe; e a pesquisa aplicada, com maiores chances de visibilidade do beneficiário da produção do pesquisador, e a pesquisa básica, distante dos olhos do beneficiário.

O conteúdo das tarefas dos trabalhadores da carreira de suporte à pesquisa, que transborda para a carreira de pesquisa, toma o sentido da sobrecarga, pois, conforme alegado nas entrevistas, tudo lhes cai sobre as costas. A tarefa da locomotiva está relacionada à ideia de desbravamento, e a do vagão, às acomodações necessárias ao andamento da atividade científica.

O ritmo da produção pode ser considerado intenso. Imprevistos foram relatados como fonte de muito estresse devido à exiguidade de tempo, percebido como insuficiente para o tamanho da demanda. Assim, a impossibilidade de lidar com as contingências aponta o estado limite do pesquisador: sobrecarregado e próximo à extenuação. A falta de tempo impacta a capacidade do pesquisador de manter atualizado seu conhecimento, particularmente, a leitura dos artigos científicos, situação percebida como nociva sua competência.

No campo do prazer, observamos que se vincula à identificação do trabalhador com o trabalho, uma vez que este oferece possibilidades de transformações favoráveis na realidade precária do outro. Constantemente desafiando o real, o pesquisador mobiliza sua subjetividade em práticas de inventividade e de astúcia, e essa situação nos permite tomar o prazer, fortemente ligado ao reconhecimento, como intenso. Na posição central da retribuição simbólica, encontra-se o beneficiário da pesquisa. Estão conjugados os chefes e os pares, cuja comunicação científica é referida como espaço privilegiado para o julgamento da beleza. Por meio racional, os pesquisadores entendem a publicação científica como modo de fortalecer suas capacidades de lutar por recursos na acirrada competição que é a ciência.

No âmbito do sofrimento, destaca-se a sobrecarga, situação traduzida pela necessidade dos pesquisadores em dar retorno e conduzindo-os à condição imaginária de não poder falhar; à rigidez de controle, internalizado e hierárquico; à exacerbação da dúvida quanto à efetividade e à qualidade do trabalho do outro, implicando em constante estado de alerta e de desconfiança, situações que corroboram para o esgotamento físico e emocional; as jornadas duplas; à dificuldade em separar o fora e o dentro do trabalho, circunstâncias da autoaceleração e; ao acúmulo de funções burocráticas e técnicas. A sobrecarga implica percepção de tempo exíguo para a demanda de trabalho quando o imprevisto se torna objeto de muito estresse, e o pouco tempo compromete a capacidade de atualização de conhecimentos, particularmente, por meio da leitura de artigos científicos.

\section{REFERÊNCIAS}

Alves, G. (2011). Trabalho, subjetividade e capitalismo manipulatório: Novo Metabolismo social do trabalho e a precarização do homem que trabalha. Revista Estudos do Trabalho, 5(8), 1-31. doi: http://dx.doi.org/10.1037/rmh0000008

Antunes, R., \& Alves, G. (2004). As mutações no mundo do trabalho na era da mundialização do capital. Educação \& Sociedade, 25(87), 335-351. doi: http://dx.doi.org/10.1037/rmh0000008

Bomfim, R. C., Soares, D. A. (2011). Percepção de enfermeiros quanto ao trabalho na unidade de terapia intensiva: Uma relação de prazer e sofrimento. Ciência \& Desenvolvimento: Revista Eletrônica da FAINOR, 4(1), 130-143. doi: http://dx.doi. org/10.1037/rmh0000008.

Câmara, R. H., \& Faria, M. F. B. (2009). Análise comparativa entre pesquisadores e profissionais de suporte à pesquisa na Embrapa: O enfoque da psicodinâmica e da ergonomia da atividade. Revista Psicologia: Organizações e Trabalho, 9(1), 29-50.

Coutinho, M. C., Magro, M. L. P. da, \& Budde, C. (2011). Entre o prazer e o sofrimento: Um estudo sobre os sentidos do trabalho para professores universitários. Psicologia: Teoria e Prática, 13(2), 154-167. doi: http://dx.doi.org/10.1037/rmh0000008

Cooper, C. L., Dewe, P. J., \& O'driscoll, M. P. (2001). Organizational stress: A review and critique of theory, research, and applications. Thousand Oaks, California: Sage.

Dejours, C. (1992). A loucura do trabalho: Estudo de psicopatologia do trabalho (5a ed. ampliada). São Paulo: Editora CortezOboré.

Dejours, C. (2004/2008a). Prefácio Avant-propos para a edição brasileira. In S. Lancman \& L. I. Sznelwar (Orgs.), Christophe Dejours da psicopatologia à psicodinâmica do trabalho (2a ed., pp. 17-23). Rio de Janeiro: Fiocruz, Brasília: Paralelo 15. 
Dejours, C. (2004/2008b). Addendum da psicopatologia à psicodinâmica do trabalho. In S. Lancman, \& L. I. Sznelwar (Orgs.), Christophe Dejours da psicopatologia à psicodinâmica do trabalho (2a ed., pp. 49-106). Rio de Janeiro: Fiocruz, Brasília: Paralelo 15.

Dejours, C. (2004/2008c). O trabalho como enigma. In S. Lancman \& L. I. Sznelwar (Orgs.), Christophe Dejours da psicopatologia à psicodinâmica do trabalho (2a ed., pp. 129-141). Rio de Janeiro: Fiocruz, Brasília: Paralelo 15.

Dejours, C. (2004/2008d). Sofrimento e prazer no trabalho: A abordagem pela psicopatologia do trabalho. In S. Lancman \& L. I. Sznelwar (Orgs.), Christophe Dejours da psicopatologia à psicodinâmica do trabalho (2a ed., pp. 143-157). Rio de Janeiro: Fiocruz, Brasília: Paralelo 15.

Dejours, C. (2004/2008e). Ativismo profissional: Masoquismo, compulsividade ou alienação? In S. Lancman, \& L. I. Sznelwar (Orgs.), Christophe Dejours da psicopatologia à psicodinâmica do trabalho (2a ed., pp. 159-177). Rio de Janeiro: Fiocruz, Brasília: Paralelo 15.

Dejours, C. (2004/2008f). Uma resposta durante o seminário "sofrimento e prazer no trabalho". In S. Lancman \& L. I. Sznelwar (Orgs.), Christophe Dejours da psicopatologia à psicodinâmica do trabalho (2a ed., pp. 179-185). Rio de Janeiro: Fiocruz, Brasília: Paralelo 15.

Dejours, C. (2004/2008g). Para uma clínica da mediação entre psicanálise e política. In S. Lancman \& L. I. Sznelwar (Orgs.), Christophe Dejours da psicopatologia à psicodinâmica do trabalho (2a ed., pp. 187-216). Rio de Janeiro: Fiocruz, Brasília: Paralelo 15.

Dejours, C. (2004/2008h). Alienação e clínica do trabalho. In S. Lancman \& L. I. Sznelwar (Org.), Christophe Dejours da psicopatologia à psicodinâmica do trabalho (2a ed., pp. 219-244). Rio de Janeiro: Fiocruz, Brasília: Paralelo 15.

Dejours, C. (2004/2008i). Inteligência prática e sabedoria prática. In S. Lancman \& L. I. Sznelwar (Org.), Christophe Dejours da psicopatologia à psicodinâmica do trabalho (2a ed., pp. 325-347). Rio de Janeiro: Fiocruz, Brasília: Paralelo 15.

Dejours, C. (2004/2008j). Entre sofrimento e reapropriação. In S. Lancman \& L. I. Sznelwar (Orgs.), Christophe Dejours da psicopatologia à psicodinâmica do trabalho (2a ed., pp. 351-364). Rio de Janeiro: Fiocruz, Brasília: Paralelo 15.

Dejours, C. (2012a). Trabalho vivo, tomo I, sexualidade e trabalho. Brasília: Paralelo 15.

Dejours, C. (2012b). Trabalho vivo, tomo II, trabalho e emancipação. Brasília: Paralelo 15.

Lambotte, M. C. (1996). Narcisismo. In M. C. Lambrotte (Org.), Dicionário enciclopédico de psicanálise: O legado de Freud e Lacan (pp. 347-356). Rio de Janeiro: Zahar.

Lazarus, R. (1990). Theory-based stress measurement. Psychological Inquiry [serial online] onelive. 1(1), 3-13. doi: 10.1207/ s15327965pli0101_1

Lazarus, R. (1993). From psychological stress to the emotions: A history of changing outlooks. Annual Review of Psychology, 44 , 1-21. doi: 10.1146/annurev.ps.44.020193.000245

Lazarus, R. (2006). Stress and emotion: A new synthesis. New York: Springer Publishing Company.

Mendes, A. M. B. (2007a). Da psicodinâmica à psicopatologia do trabalho. In A. M. B. Mendes (Org.), Psicodinâmica do trabalho: Teoria, método e pesquisas (pp. 29-48). São Paulo: Casa do Psicólogo.

Mendes, A. M. B. (2007b). Novas formas de organização do trabalho, ação dos trabalhadores e patologias sociais. In A. M. B. Mendes (Org.), Psicodinâmica do trabalho: Teoria, método e pesquisas (pp. 49-61). São Paulo: Casa do Psicólogo.

Mendes, A. M. B. (2007c). Pesquisa em psicodinâmica do trabalho: A clínica do trabalho. In A. M. B. Mendes (Org.), Psicodinâmica do trabalho: teoria, método e pesquisas (pp. 65-87). São Paulo: Casa do Psicólogo.

Mendes, A. M. B. (2008). A organização do trabalho como produto da cultura e a prevenção do estresse ocupacional: O olhar da psicodinâmica do trabalho. In A. Tamayo (Org.), Estresse e cultura organizacional (pp. 164-192). São Paulo: Casa do Psicólogo.

Mendes, A. M. B., \& Araújo, L. K. R. (2011). Por uma clínica psicodinâmica do trabalho. In A. M. B. Mendes \& L. K. R. Araújo (Orgs.), Clínica psicodinâmica do trabalho: práticas brasileiras (pp. 47-79). Brasília: Ex Libris.

Mendes, A. M. B, \& Araújo, L. K. R. (2012). O sujeito em ação: Diálogos entre a psicodinâmica do trabalho e a psicanálise. In A. M. B. Mendes \& L. K. R. Araújo. Clínica psicodinâmica do trabalho: o sujeito em ação (pp. 21-37). Curitiba: Juruá.

Mendes, A. M. B., Paz, V. C., \& Barros, P. C. R. (2003). Estratégias de enfrentamento do sofrimento no trabalho bancário. Estudos e Pesquisa em Psicologia, 3(1), 59-72.

Merlo, A.R.C. \& Mendes, A. M. (2009). Perspectivas do uso da psicodinâmica do trabalho no Brasil: Teoria, pesquisa e ação. Cadernos de Psicologia Social do Trabalho, 12(2), 141-156. doi: http://dx.doi.org/10.11606/issn.1981-0490.v12i2p141-156. 
Ministério do Trabalho e Emprego. (2010). Classificação Brasileira de Ocupações (CBO) (3a ed.). Secretaria de Políticas Públicas de Emprego: Brasília. Recuperado de http://www.mtecbo.gov.br/cbosite/pages/downloads.jsf

Peçanha, D. L. N. (2009). Cultura organizacional e saúde: Contribuições da psicodinâmica do trabalho. Boletim Academia Paulista de Psicologia, São Paulo, 29(2), 329-344. doi: http://dx.doi.org/10.1037/rmh0000008

Pinto, G. A. (2010). A organização do trabalho no século 20: Taylorismo, fordismo e toyotismo. São Paulo: Editora Expressão Popular.

Rego, V. B. (2013). Aceleração. In F. O. Vieira, A. M. Mendes, \& A. R. C. Merlo (Orgs.), Dicionário crítico de gestão e psicodinâmica do trabalho (pp.33-37). Curitiba: Juruá.

Sardá, J. J. Jr., Legal, E., \& Jablonski, S. Jr. (2003). Estresse: Conceitos, métodos, medidas e possibilidades de intervenção (Coleção Temas em Avaliação). São Paulo: Casa do Psicólogo.

Schirato, M. A. R. (2004). O feitiço das organizações: sistemas imaginários. São Paulo: Atlas.

Segnini, M. P., \& Lancman, S. (2011). Sofrimento psíquico do bailarino: Um olhar da psicodinâmica do trabalho. Revista Laboreal, 7(1). Recuperado de http://laboreal.up.pt/revista/artigo.php?id=37t45nSU54711247559512143:1.

Selye, H. (1950). Stress and the general adaptation syndrome. British Medical Journal. 1(4667), 1383-1392. Recuperado de http://www.bmj.com/content/1/4667/1383.full.pdf

Silva, E. A., \& Costa, I. I. (2010). O profissional de referência em saúde mental: das responsabilizações ao sofrimento psíquico. Revista Latinoamericana de Psicopatologia Fundamental, São Paulo, 13(4), 635-647. doi: http://dx.doi.org/10.1590/S141547142010000400007.

Uchida, S. (1998). Trabalho informatizado e sofrimento psíquico. Psicologia USP, 9 (2), 179-204. doi: http://dx.doi.org/10.1037/ rmh0000008

Zanelli, J. C. (Coord.). (2010). Estresse nas organizações de trabalho: Compreensão e intervenção baseadas em evidências. Porto Alegre: Artmed. 